\title{
Quantitative risk analysis for road tunnels complying with EU regulations
}

\author{
Konstantinos KIRYTOPOULOS ${ }^{1, *}$, Athanasios RENTIZELAS ${ }^{2}$, Ilias \\ TATSIOPOULOS ${ }^{3}$, George PAPADOPOULOS ${ }^{4}$
}

${ }^{1}$ Assistant Professor, Financial and Management Engineering Dept, University of the Aegean, Kountouriotou 41, 82100, Chios, Greece.

${ }^{2}$ Researcher, Mechanical Engineering School, National Technical University of Athens, Iroon Polytechniou 9, 15780, Athens, Greece.

${ }^{3}$ Professor, Mechanical Engineering School, National Technical University of Athens, Iroon Polytechniou 9, 15780, Athens, Greece.

${ }^{4}$ Researcher, Mechanical Engineering School, National Technical University of Athens, Iroon Polytechniou 9, 15780, Athens, Greece.

*corresponding author: kkir@central.ntua.gr

Abstract

Tunnels have improved the connection of regions within the EC and have been used lately as a catalyst for economic development of previously isolated regions. However, the increasing number of these important infrastructures is raising upfront an endogenous problem which is the severity of accidents that may occur. These risks have much greater impact when heavy goods vehicles or dangerous goods are involved in the accident.

As a result, the European Commission launched the EC Directive 2004/54/EC. In order to achieve a minimum acceptable level of safety, the EC Directive 2004/54/EC suggests, apart from the measures imposed based on tunnel characteristics, the implementation of a risk analysis in cases such as the opening of the road tunnel to dangerous goods. The most widely accepted method for such quantitative risk analysis is the OECD /PIARC QRA Model.

This research uses the Model to perform a quantitative risk analysis for five illustrative cases in order to explore the sufficiency of the minimum tunnel safety measures imposed by the Directive when transportation of heavy goods vehicles and dangerous goods is allowed through the tunnel. The research concludes that, at least for tunnels with marginal values of the EC Directive classes for length and traffic, the risk exposure $(\mathrm{F} / \mathrm{N}$ curves) lays over the acceptable safety limits of ALARP models. Thus, the manager of the tunnel should consider more safety measures and take into account the risk associated with the alternative routes.

Keywords: road tunnel, risk analysis, quantitative analysis, safety, ALARP, dangerous goods

\section{Introduction}


Existence of tunnels has boosted opportunities in transportation of individuals but mainly of goods. Tunnels have improved the connection of regions within the EC and have been used lately as a catalyst for economic development of previously isolated regions. However, the increasing number of these important infrastructures is raising upfront an endogenous problem which is the severity of accidents that may occur. Accidents in tunnels, fire been the most significant, may lead to heavy consequences for users, the infrastructure itself as well as the environment. Especially when transportation of dangerous goods is allowed through a road tunnel, the consequences of a possible accident take the form of a societal risk due to its potential extensive impact.

These heavy consequences may explain the increased attention these accidents have received in relation to similar accidents in open road. Despite the fact that the frequency of such accidents is very low, the impact they have is usually attracting the interest of media and the public. This interest was certainly augmented by quite a number of major tunnel fires such as the Mont Blanc and Tauern disasters (1999), the Kaprun tragedy (2000), the Gleinalm tunnel fire (2001) and St Gotthard tunnel fire (2001) which caused fatalities and severe traffic restrictions (European Thematic Network Fire In Tunnels, 2007).

The most severe road tunnel accident until now is the Mont Blanc Tunnel disaster in 1999. According to Haack (2002) a refrigerator lorry carrying margarine and flour caught fire within the $11.6 \mathrm{~km}$ long tunnel which led to a fully-fledged fire, which spread to involve 23 lorries and 10 cars, resulting to the death of 39 persons. Concerns are expressed for the adequacy of the ventilation system as well as the whole system of safety measures and procedures, as the tunnel was designed many years ago. 
During the same year and less than 3 months after the Mont Blanc Tunnel disaster, the Tauern Tunnel disaster came to take place. According to Leitner (2001), construction works kept one lane of the tunnel closed, thus the other operated in both directions when a truck crashed with full speed into the waiting queue, which led to a fire that quickly spread to a lorry carrying a variety of goods included aerosols containing hair spray. The accident led to a huge fire catastrophe and the death of 12 persons.

Some years later, two other fires in road tunnels caused casualties. The Gotthard Tunnel accident took place in 2001 when a truck driver lost control of his vehicle, probably because of severe alcohol abuse, and crashed into an oncoming Heavy Goods Vehicle $(H G V)$ that caught fire, which spread to seven other $H G V s$, causing tremendous masses of smoke because of the highly energetic fire loads, finally resulting to the death of 11 persons (Carvel et al., 2005). The Gleinalm Tunnel accident occurred when a car hit an oncoming mini bus and both vehicles caught fire immediately resulting to the death of five persons (Carvel et al., 2005).

The common characteristic of all these accidents is that all occurred in long $(>6 \mathrm{~km})$ single bore tunnels. Moreover, the aforementioned accidents, apart from the direct impact, also lead to heavy disruption on the normal routes of goods and individual transportation and sometimes lead to added traffic congestion in alternative routes and in turn, to a further rise in accident risks (Haack, 2002) for many months or even years after the disaster.

Due to these and other high impact accidents in road tunnels, the European Commission concluded, after years of consultations, to the EC Directive 2004/54/EC entitled "minimum safety requirements for tunnels in the trans-European road network". The Directive lays down a set of harmonised minimum safety standards 
dealing with the various organisational, structural, technical and operational aspects. The aim of the Directive is to ensure that all tunnels longer than 500 metres, whether in operation, under construction or at the design stage, which form part of the TransEuropean Road Network, comply with the new harmonised safety requirements.

In order to achieve a minimum acceptable level of safety, the EC Directive 2004/54/EC suggests, apart from the measures imposed based on tunnel characteristics, the implementation of a risk analysis in cases such as the opening of the road tunnel to dangerous goods. However, the Directive does not indicate either the method for performing the risk analysis or the criteria for risk acceptance. Thus, each country / administrative authority or even each tunnel manager may select the appropriate method of analysis as well as the criteria for risk acceptance. The method that seems to be the most widely accepted by administrative authorities for quantitative risk analysis is the OECD /PIARC QRA Model.

The research problem that this paper addresses is whether the minimum tunnel safety measures imposed by the EC Directive 2004/54/EC are sufficient to lead to acceptable typical societal risk levels, as defined through the ALARP limits for the transportation of dangerous goods, when evaluated using the OECD /PIARC QRA Model. The research is based on the examination of five illustrative and representative case studies, which represent the various tunnel classes of the EC Directive. It should be mentioned here that $\mathrm{HGVs}$ that do not carry dangerous goods but may lead to significant fires (greater than 20MW) when involved in an accident have been included in the analysis presented in this work. This type of HGVs form the first two scenarios (scenario 1 and 2) of the OECD /PIARC QRA Model and for the purposes of this work the term "dangerous goods" will also include this category of HGVs. 
The rest of this paper is structured as follows. The second section presents the literature review for the use of OECD /PIARC QRA Model in risk analysis of road tunnels. The third section offers the description of the OECD /PIARC QRA Model as far as the input data are concerned. The fourth section, Research Findings, is divided in three subsections dealing with the pilot case description, the safety measures enforced by the EC Directive 2004/54/EC and the QRA model results respectively. The paper concludes with a discussion section which summarises the findings of the research, stresses limitations of the model and proposes actions to be taken by the administrative authorities when analysing the risk of road tunnels.

\section{Use of OECD / PIARC QRA Model}

The OECD / PIARC QRA Model has been developed by INERIS, WS-Atkins and the Institute for Risk Research (Knoflacher, 2001; Knoflacher and Pfaffenbichler, 2001;

OECD, 2001). The version of the Model used in this work is the currently latest QRAM-DG 3.61 version. The model consists of spreadsheet-based tools and a Fortran program for some finer results. It is aimed at being simple to use, but experts may make changes to take account of specific situations or data (Lacroix et al. 1999). The Model is already used in several European Countries (PIARC, 2008). For example, the safety regulations in France foresee the use of the model for the investigation of risk of transportation of dangerous goods, instead of the "Specific Hazard Investigation" method that has been developed and is used for other types of risk. Austria, also uses the OECD / PIARC QRA model when transportation of dangerous goods is allowed through road tunnels. The Czech Republic incorporated the EU Directive 2004/54/EC on minimum safety requirements for tunnels with the national law 80/2006 and officially addresses the risk for the transportation of dangerous goods with the OECD / PIARC QRA model. 
Germany, uses the OECD / PIARC QRA model for the quantitative analysis of risk for dangerous goods transportation, as well. Finally, in Greece, the use of the OECD / PIARC QRA Model has been proposed by the Greek tunnel administrative authority as the most suitable method for risk analysis when transportation of dangerous goods is allowed through a tunnel, but the proposal has not been officially approved by the State yet.

The outcome of the Model is the Individual Risk as well as the relevant F/N curves for fatalities and injuries. $\mathrm{F} / \mathrm{N}$ curves present graphically the frequency (F) of accidents with $\mathrm{N}(\mathrm{N})$ or more victims, where $N$ ranges upward from 1 to the maximum possible number of victims in the system (Evans, 2003). The evaluation of the tunnel based on the $\mathrm{F} / \mathrm{N}$ curves provided by the model is usually made either on a comparative basis (comparison to alternative routes) or according to the positioning of the F/N curves compared to the ALARP limits. The ALARP limits are based on the rationale that there is a low risk region, below a specific frequency of occurrence, where risk may be considered tolerable, or equivalently the risk may be considered negligible. There is also a high risk region, over a specific frequency, where the risk is considered intolerable and therefore unacceptable. In this case measures for reducing the risk have to be taken to allow the use of the tunnel, irrespective of the cost. Between these two limits lies the ALARP region, where the operation of the tunnel is not prohibited (Figure 1). However, all measures that may reduce the risk and the consequences of accidents should be examined, taking also into account the resulting cost, therefore selecting those measures that do not have disproportional cost compared to the benefit they will offer (Safe-T, 2008). 


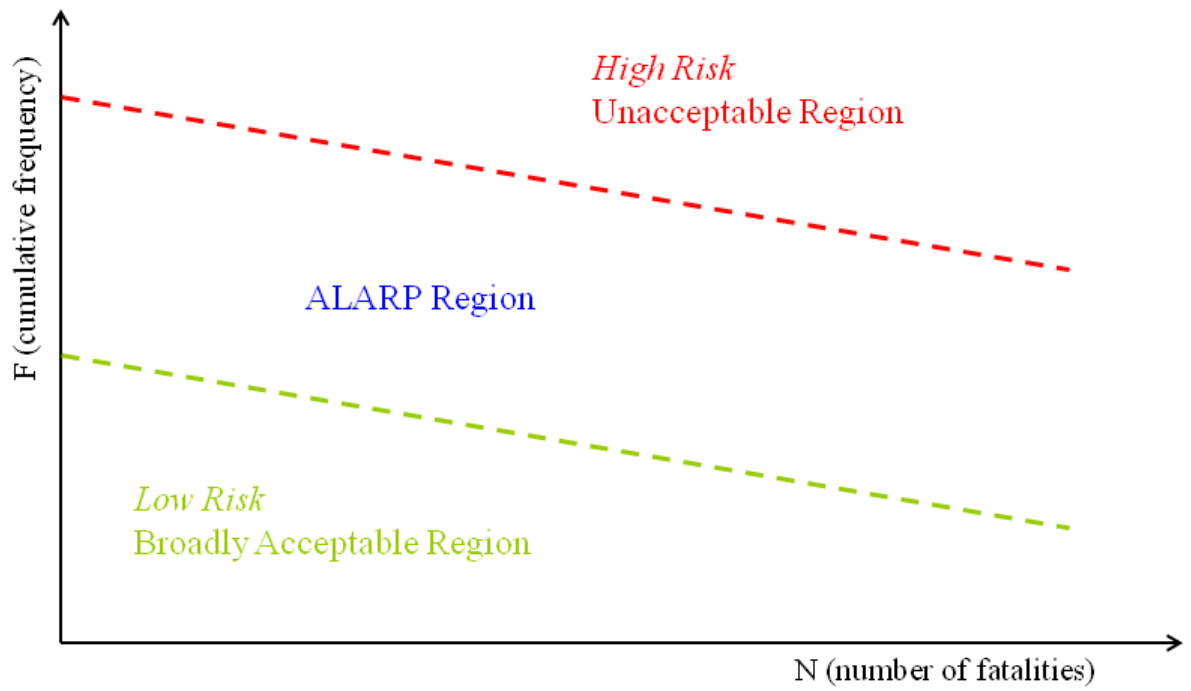

Figure 1. The ALARP Region

The literature concerning the use of the OECD / PIARC QRA Model is not as extensive as one would expect, compared to the extent of its use. Knoflacher et al. (2002) have used the OECD / PIARC QRA Model to examine the potential risk reduction of implementing improved safety measures for two case studies (the Tauern and the Mont Blanc tunnels). The proposed safety measures studied were improved emergency ventilation and imposing increased distance between HGVs respectively. The QRA Model results revealed that both measures had significant potential to reduce the risk caused by HGVs in tunnels. The OECD / PIARC QRA Model has also been used in Parsons Brinckerhoff Quade \& Douglas (2006) to compare the risk involved in allowing Dangerous Goods HGVs through the Eisenhower/Johnson Memorial Tunnels, compared to an alternative route. The specific work concluded 
that, based on the results of the model, the current policy of routing Dangerous Goods HGVs on the alternative of the tunnels route should be maintained.

Despite the fact that the OECD / PIARC QRA Model is recognized as the industrystandard (Parsons Brinckerhoff Quade \& Douglas, 2006), research has also been performed, using other types of models. In the work of Bubbico et al. (2006) a Transportation Risk Analysis tool (developed by Bubbico et al. 2004) has been utilized, to perform an assessment of the risk associated to a variety of road and rail transportation cases representative of hazardous materials transport by land in Sicily. Furthermore, the effect of several mitigation measures to the risk has been examined quantitatively. In the work of Pálsson (2004), prior to the release of the OECD / PIARC QRA Model software, the author performs a Quantitative Risk Analysis of a tunnel in Iceland taking into account the uncertainty of the input values, by using a Monte Carlo simulation technique.

As it can be deduced from the above literature research, most publications relevant to the OECD / PIARC QRA Model refer to case studies. Thus, the research gap identified here is that the sufficiency of the EU minimum safety requirements for tunnels in the trans-European road network for the transportation of dangerous goods has not been studied as a standalone issue. The rest of this paper attempts to quantify the risk levels of tunnels complying to the EU minimum safety requirements, when transportation of dangerous goods is allowed through them, and to reveal whether these risk levels are below the accepted societal risk levels. In order to examine the worst case scenarios, marginal values of the EC Directive classes have been selected for the traffic and length of the cases examined.

\section{OECD /PIARC QRA Model description}


The OECD/PIARC QRA Model is used to assess quantitatively the societal risk of transporting goods and dangerous goods with Heavy Goods Vehicles (HGV) through road tunnels (INERIS, 2005). The model consists of a limited number of scenarios concerning the potential dangerous goods categories and potential accident types and evaluates simultaneously their consequences and frequency. Despite the fact that the model does not include all potential dangerous goods, it is considered a relatively good approximation of the reality, as it includes representative scenarios for the major categories of hazardous materials (Knoflacher et al, 2002). Furthermore, it offers the option for the inclusion of a customized category of Dangerous Goods (DG) that is not included by default in the model.

The inputs of the model can be grouped into several categories. First of all, the user has to identify the Dangerous Goods categories that will be included in the calculations, as well as quantitative data for the proportion of each Dangerous Good type to the DG-HGV traffic. The user may also decide on whether the non-DG HGV traffic will be taken into account when calculating the risk (scenarios 1 and 2 of the Model).

A second category of inputs is the traffic characteristics of the route under investigation and the population data for the region surrounding the route. The traffic characteristics can be defined for up to three different time-periods, to allow for seasonally higher traffic rates. Additionally, the accident rates for the routes examined have to be defined.

Finally, the user has to include a description of the route characteristics, as well as construction details for all the tunnels included in the route. The details for tunnels include geometrical characteristics (gradient, length, cross-sectional area, camber 
etc.), information about safety equipment (mechanical ventilation design and operational characteristics, drainage, emergency exits, surveillance systems and emergency communications etc.) as well as information on the tunnel structure.

\section{Research Findings}

\section{Pilot case description}

The research is based on the examination of five illustrative and representative case studies, which represent the various tunnel classes of the EC Directive 2004/54/EC. It is important to note that all case studies aim to simulate rural road tunnels. Each case study has been selected to represent one of the tunnel classes of the EC Directive, in terms of traffic and length of the tunnels. In order to examine the worst case scenarios, marginal values of the EC Directive classes have been selected for the traffic and length of the cases (refer to Table 1). For cases 3 to 5, a relatively high value of traffic has been selected (20000 vehicles/day) to represent the usual traffic of the major rural motorways in Greece. The length of tunnel case $5(4600 \mathrm{~m})$ has been chosen equal to the longest existing road tunnel in Greece. The tunnels examined in this research are of similar design and construction characteristics. Depending on the classification of the tunnel according to the EC Directive, the safety equipment of the tunnel has been chosen to comply with the minimum provisions of the Directive for the respective class.

As far as the design and construction characteristics of the tunnels examined are concerned, a typical design of two tubes (uni-directional) with two lanes per tube without emergency lanes has been adopted. This design is the most common in new tunnels being designed or constructed in Greece for the last years (Greece will be ranked fourth among EU-15 members in number of tunnels with length greater than 
$500 \mathrm{~m}$ after the year 2010). The cross-sectional area of the tunnels has been assumed equal to $64 \mathrm{~m}^{2}$, the internal radius to $5,5 \mathrm{~m}$, the gradient is set to zero degrees and the camber to $2,5 \%$. The lining, as well as the road support thickness have been assumed equal to $0,3 \mathrm{~m}$. The drainage is performed by discrete drains of open area $0,09 \mathrm{~m}^{2}$ which are located every $25 \mathrm{~m}$. The construction of the tunnel is by drilling and blasting/TBM in bedrock type of ground, which is the typical case for long tunnels in Greece. The overburden depth is assumed equal to $100 \mathrm{~m}$, without the presence of water over the solid overburden.

\section{Safety measures enforced by EC Directive 2004/54/EC}

Table 1 shows the major characteristics of each case study examined. The first part of the table concerns the major characteristics of each tunnel, length and traffic, and the corresponding EC Directive 2004/54/EC class each case falls into. The second part contains all the safety measures foreseen in the EC Directive that change for the various cases. Safety measures that are obligatory for all tunnel classes are not presented in the table.

Table 1: Description of the five cases examined

\begin{tabular}{|c|c|c|c|c|c|c|}
\hline \multicolumn{2}{|l|}{ Cases } & \multirow{2}{*}{$\begin{array}{l}\text { Case } 1 \\
999\end{array}$} & \multirow{2}{*}{$\begin{array}{l}\text { Case } 2 \\
2999\end{array}$} & \multirow{2}{*}{$\begin{array}{l}\text { Case } 3 \\
999\end{array}$} & \multirow{2}{*}{$\begin{array}{l}\text { Case } 4 \\
2999\end{array}$} & \multirow{2}{*}{$\begin{array}{l}\text { Case } 5 \\
4600\end{array}$} \\
\hline & Length (m) & & & & & \\
\hline & $\begin{array}{l}\text { Traffic } \\
\text { (veh/day*lane) }\end{array}$ & 1999 & 1999 & 5000 & 5000 & 5000 \\
\hline & $\begin{array}{l}\text { Corresponding } \\
\text { 2004/54/EC } \\
\text { category }\end{array}$ & $\begin{array}{l}\operatorname{Tr}<2000 \\
500<L<100 \\
0\end{array}$ & $\begin{array}{l}T r<2000 \\
L>1000\end{array}$ & $\begin{array}{l}\operatorname{Tr}>2000 \\
500<L<100 \\
0\end{array}$ & $\begin{array}{l}\operatorname{Tr}>2000 \\
1000<L<30 \\
00\end{array}$ & $\begin{array}{l}T r>2000 \\
L>3000\end{array}$ \\
\hline \multirow{3}{*}{$\begin{array}{c}\text { Structural } \\
\text { measures }\end{array}$} & Emergency exits & $\mathrm{N}$ & $\mathrm{N}$ & Every 500m & Every 500m & Every 500m \\
\hline & $\begin{array}{l}\text { Cross-connections } \\
\text { for emergency } \\
\text { services }\end{array}$ & $\mathrm{N}$ & $\begin{array}{l}\text { Every } \\
1500 \mathrm{~m}\end{array}$ & $\mathrm{~N}$ & $\begin{array}{l}\text { Every } \\
1500 \mathrm{~m}\end{array}$ & $\begin{array}{l}\text { Every } \\
1500 \mathrm{~m}\end{array}$ \\
\hline & Control center & $\mathrm{N}$ & $\mathrm{N}$ & $\mathrm{N}$ & $\mathrm{N}$ & $\mathrm{Y}$ \\
\hline
\end{tabular}




\begin{tabular}{|c|c|c|c|c|c|c|}
\hline \multirow{2}{*}{$\begin{array}{l}\text { Monitoring } \\
\text { systems }\end{array}$} & Video & $\mathrm{N}$ & $\mathrm{N}$ & $\mathrm{N}$ & $\mathrm{N}$ & Y \\
\hline & $\begin{array}{l}\text { Automatic Incident } \\
\text { detection and/or fire } \\
\text { detection }\end{array}$ & $\mathrm{Y}$ & $\mathrm{Y}$ & Y & $\mathrm{Y}$ & Y \\
\hline \multirow[t]{3}{*}{ Ventilation } & $\begin{array}{l}\text { Mechanical } \\
\text { Ventilation }\end{array}$ & $\mathrm{N}$ & $\mathrm{N}$ & $\mathrm{N}$ & $\mathrm{Y}$ & $\mathrm{Y}$ \\
\hline & $\begin{array}{l}\text { Normal Operation } \\
\left(\mathrm{m}^{3} / \mathrm{s}\right)\end{array}$ & 0 & 0 & 0 & 0 & 0 \\
\hline & $\begin{array}{l}\text { Emergency } \\
\text { operation }\left(\mathrm{m}^{3} / \mathrm{s}\right)\end{array}$ & 0 & 0 & 0 & 196 & 225 \\
\hline \multirow{3}{*}{$\begin{array}{l}\text { Equipment } \\
\text { to close the } \\
\text { tunnel }\end{array}$} & $\begin{array}{l}\text { Traffic signals } \\
\text { before entrance }\end{array}$ & $\mathrm{N}$ & $\mathrm{Y}$ & $\mathrm{N}$ & $\bar{Y}$ & $\mathrm{Y}$ \\
\hline & $\begin{array}{l}\text { Traffic signals } \\
\text { inside tunnel }\end{array}$ & $\mathrm{N}$ & $\mathrm{N}$ & $\mathrm{N}$ & $\mathrm{N}$ & Y \\
\hline & $\begin{array}{ll}\text { Radio } & \text { re- } \\
\text { broadcasting for } & \text { for } \\
\text { emergency services }\end{array}$ & $\mathrm{N}$ & $\mathrm{N}$ & $\mathrm{N}$ & Y & Y \\
\hline
\end{tabular}

Several design characteristics that are common to all tunnel cases are not presented in

Table 1. It is assumed that all tunnels have emergency walkways, as they do not have an emergency lane, and that there is a possibility of crossing of the central reserve outside each portal. The normal, safety and evacuation lighting is mandatory for all tunnel cases and is designed and installed according to the relevant regulations and norms. The emergency stations and water supply points are assumed to be installed every $150 \mathrm{~m}$ and $250 \mathrm{~m}$ respectively. The road signs for safety facilities are common for all the tunnel categories. Finally, emergency power supply and fire resistance of basic safety equipment is assumed to exist for all the tunnels examined. Table 2 shows detailed traffic-related data that are common for all cases.

Table 2. Detailed traffic-related data

\begin{tabular}{lc}
\hline Traffic-related data & \\
\hline HGV traffic (\% of total traffic) & 15 \\
Bus traffic (\% of total traffic) & 1,5 \\
Average number of persons in a car & 1,85 \\
Average number of persons in a HGV & 1.17
\end{tabular}


It is important to mention here that the inputs of the OECD/PIARC QRA model are not always directly related to the EC Directive 2004/54/EC provisions. For example, the QRA model requires the time required to close the traffic to the tunnel as an input. This value has been estimated based on the existence or absence of control center, monitoring systems (video), automatic incident and/or fire detection, traffic signals before the entrance of the tunnel and / or inside the tunnel. For cases 1 to 4 , the time required to close the tunnel for the approaching traffic has been assumed equal to 30 min whereas this time has been reduced to $5 \mathrm{~min}$ for Case 5 , due to the existence of control center and video surveillance system that may radically reduce response time.

Similarly, the time to activate the emergency ventilation in Cases 4 and 5 , where mechanical ventilation is obligatory, has been assumed to be $30 \mathrm{~min}$ and $5 \mathrm{~min}$ respectively. The reason is that in Case 5 there will be a control center and therefore the time required to activate the emergency ventilation remotely will be significantly less than in Case 4, where the activation of the emergency ventilation will have to be performed manually.

\section{QRA model results}

The following charts show the results of the OECD/PIARC QRA model for the five case studies examined. The charts show the F/N curve for the overall traffic of HGVs (All Scenarios) as well as the risk of each of the DG main categories (separate F/N curves). Furthermore, the British and Austrian ALARP limits are shown, as well as the Dutch limit. British, Austrian and Dutch limits have been adopted from Moonis et al. (2001), Knoflacher and Pfaffenbichler (2004) and PIARC (2008), respectively. 


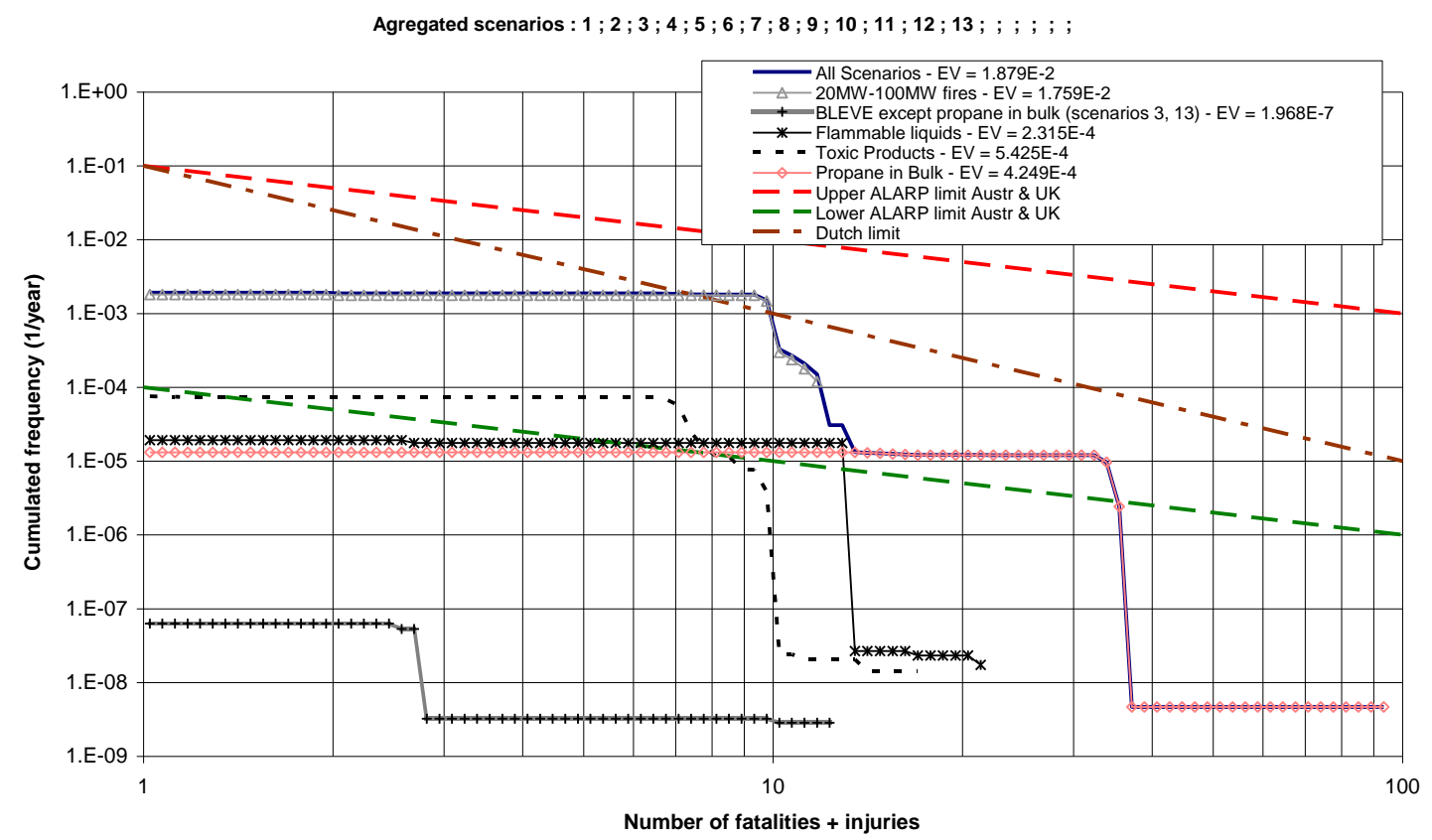

Figure 2. F/N curve for Case 1 (Length 999m and traffic 1999 vehicles/lane)

The F/N curve of Case 1 (refer to Figure 2) remains mostly (for less than 32 victims) within the ALARP region. The main cause of risk for accidents with less than 12 casualties is the Heavy Goods Vehicles without Dangerous Goods. The maximum potential number of casualties is 93 , which is a potential result of an accident of transporting propane in bulk. It should be mentioned though that for accidents with more than 32 casualties the risk is negligible, as the F/N curve lies below the lower ALARP limit. 
Agregated scenarios : $1 ; 2 ; 3 ; 4 ; 5 ; 6 ; 7 ; 8 ; 9 ; 10 ; 11 ; 12 ; 13 ; ; ; ; ;$;

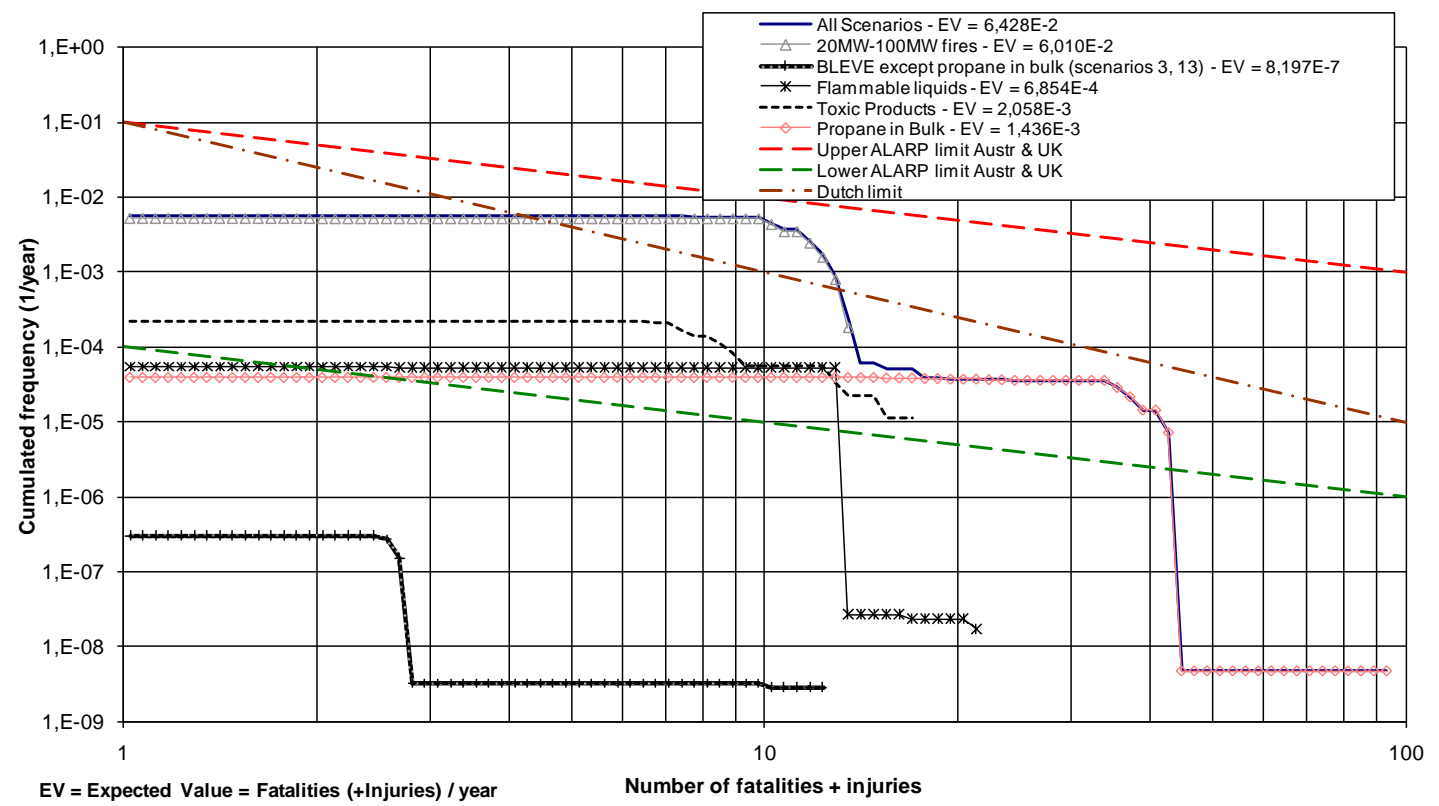

Figure 3. F/N curve for Case 2 (Length 2999m and traffic 1999 vehicles/lane)

The F/N curve of Case 2 (refer to Figure 3) remains marginally under the upper ALARP limit. The main cause of risk for accidents with less than 14 casualties is the Heavy Goods Vehicles without Dangerous Goods. The maximum potential number of casualties is 93 , which is a potential result of an accident of transporting propane in bulk. The F/N curve lies below the lower ALARP limit for accidents with more than 42 casualties. 


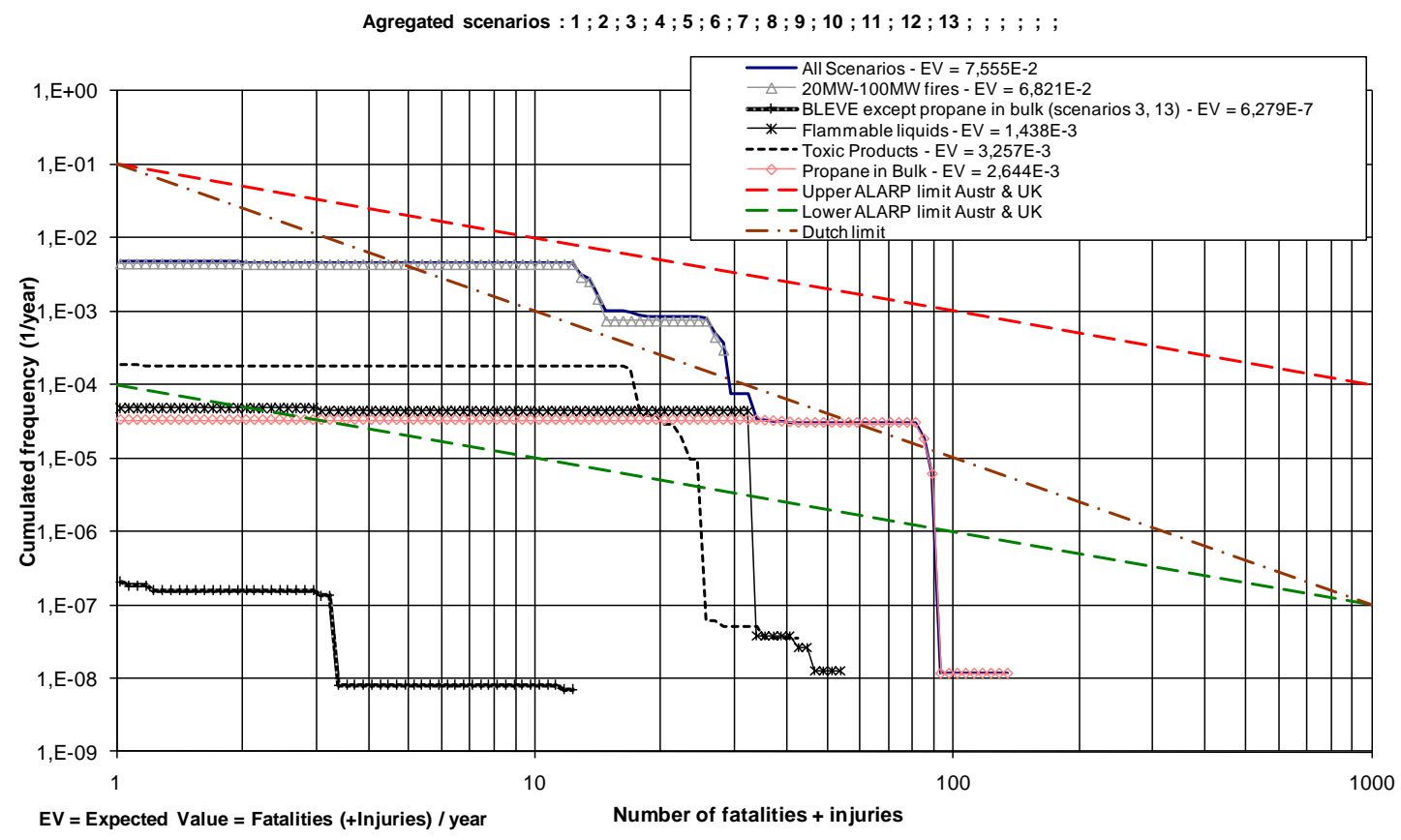

Figure 4. F/N curve for Case 3 (Length $999 \mathrm{~m}$ and traffic 5000 vehicles/lane)

The F/N curve of Case 3 (refer to Figure 3 ) also remains marginally within the ALARP region. The main cause of risk for accidents with less than 30 casualties is the Heavy Goods Vehicles without Dangerous Goods. The maximum potential number of casualties is 135 , which is a potential result of an accident of transporting propane in bulk. The F/N curve lies below the lower ALARP limit only for accidents with more than 90 casualties. 


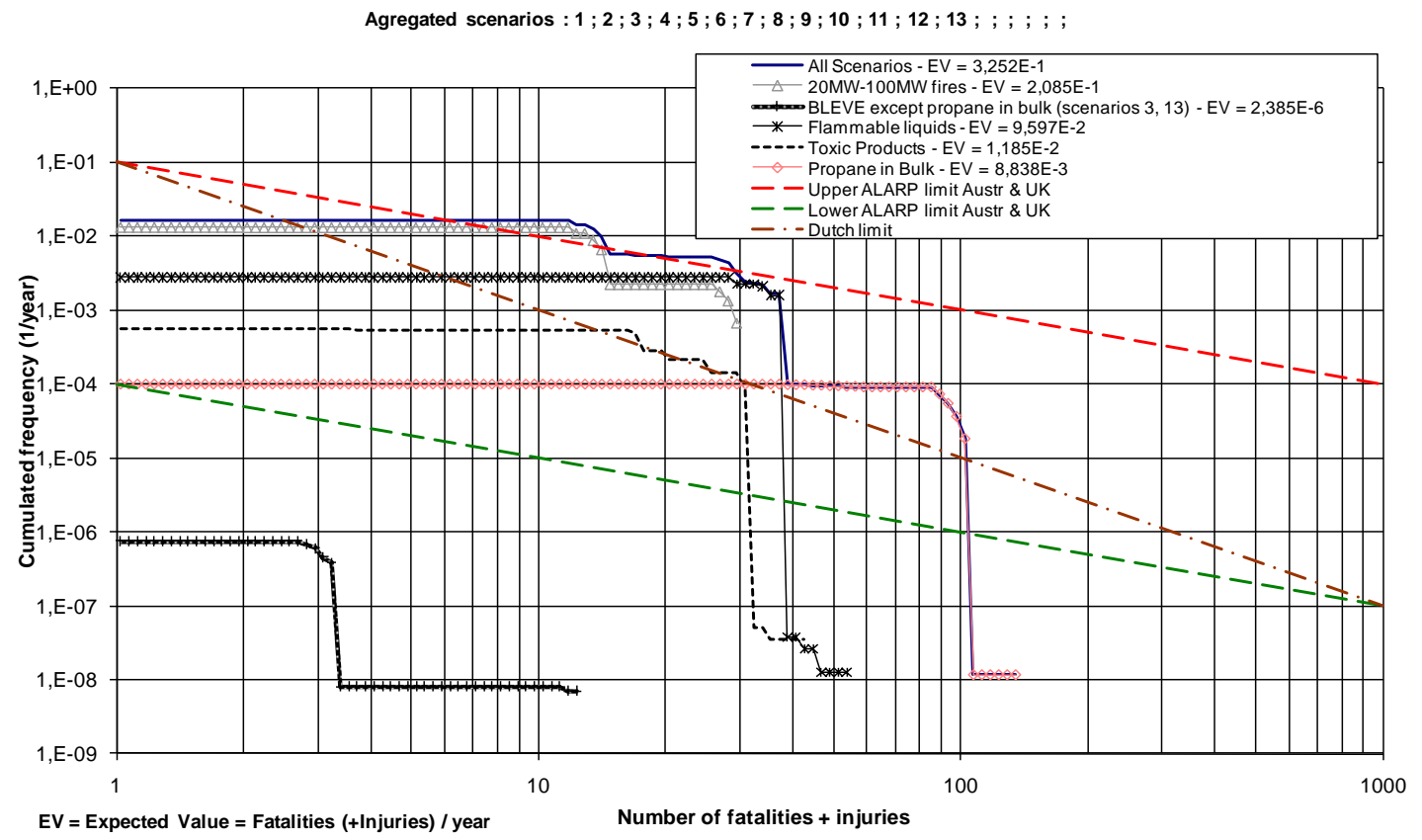

Figure 5. F/N curve for Case 4 (Length 2999m and traffic 5000 vehicles/lane)

The F/N curve of Case 4 (refer to Figure 5) exceeds the upper ALARP limit for accidents with 6 to 30 casualties, which means that the risk is intolerable and that measures for risk reduction should be taken. The main cause of risk for accidents with less than 14 casualties is the Heavy Goods Vehicles without Dangerous Goods. For accidents with 14 to 38 casualties the main cause of risk is the flammable liquids transportation. The maximum potential number of casualties is 135 , which is a potential result of an accident of transporting propane in bulk. The F/N curve lies below the lower ALARP limit only for accidents with more than 105 casualties. 


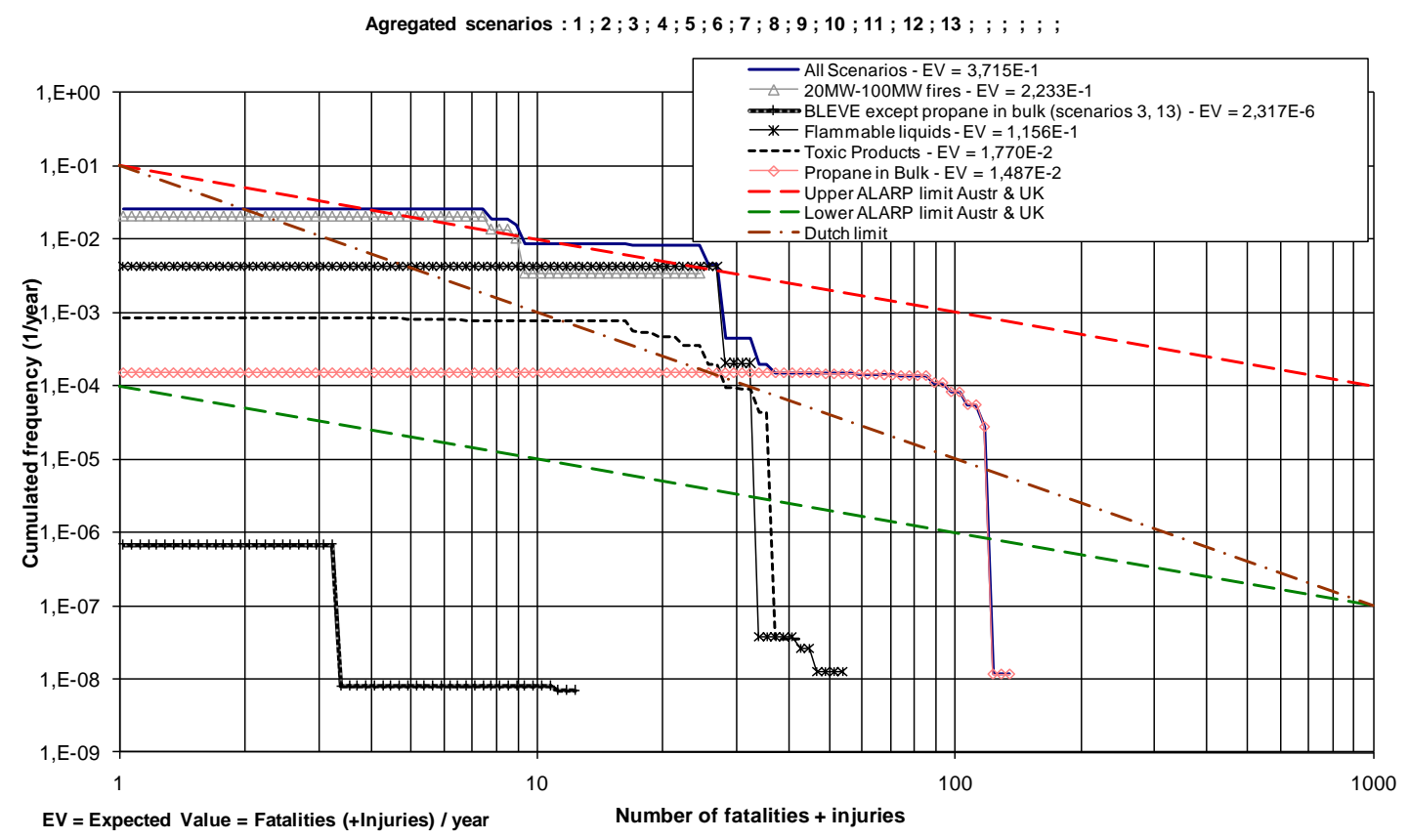

Figure 6. F/N curve for Case 5 (Length $4600 \mathrm{~m}$ and traffic 5000vehicles/lane)

The F/N curve of Case 5 (refer to Figure 6) also exceeds the upper ALARP limit for accidents with 4 to 26 casualties, which means that the risk is intolerable and that measures for risk reduction should be taken. The main cause of risk for accidents with less than 9 casualties is the Heavy Goods Vehicles without Dangerous Goods. For accident with 9 to 32 casualties the main cause of risk is the flammable liquids transportation. The maximum potential number of casualties is 135 , which is a potential result of an accident of transporting propane in bulk. The $\mathrm{F} / \mathrm{N}$ curve practically lies over the upper ALARP limit or within the ALARP for all its length.

\section{Discussion}

\section{Research findings}

The safety measures imposed by 2004/54/EC may be sufficient for light vehicles but the quantitative risk analysis for heavy goods as well as dangerous goods vehicles shows that F/N curves lay higher than the lower ALARP limit, for all cases under 
examination. This means that stricter safety measures than those imposed by 2004/54/EC should always be considered, if heavy goods and/ or dangerous goods pass through the tunnel. The summary of findings for the five case studies analysed with OECD /PIARC QRA Model in this research are offered in Figure 7.

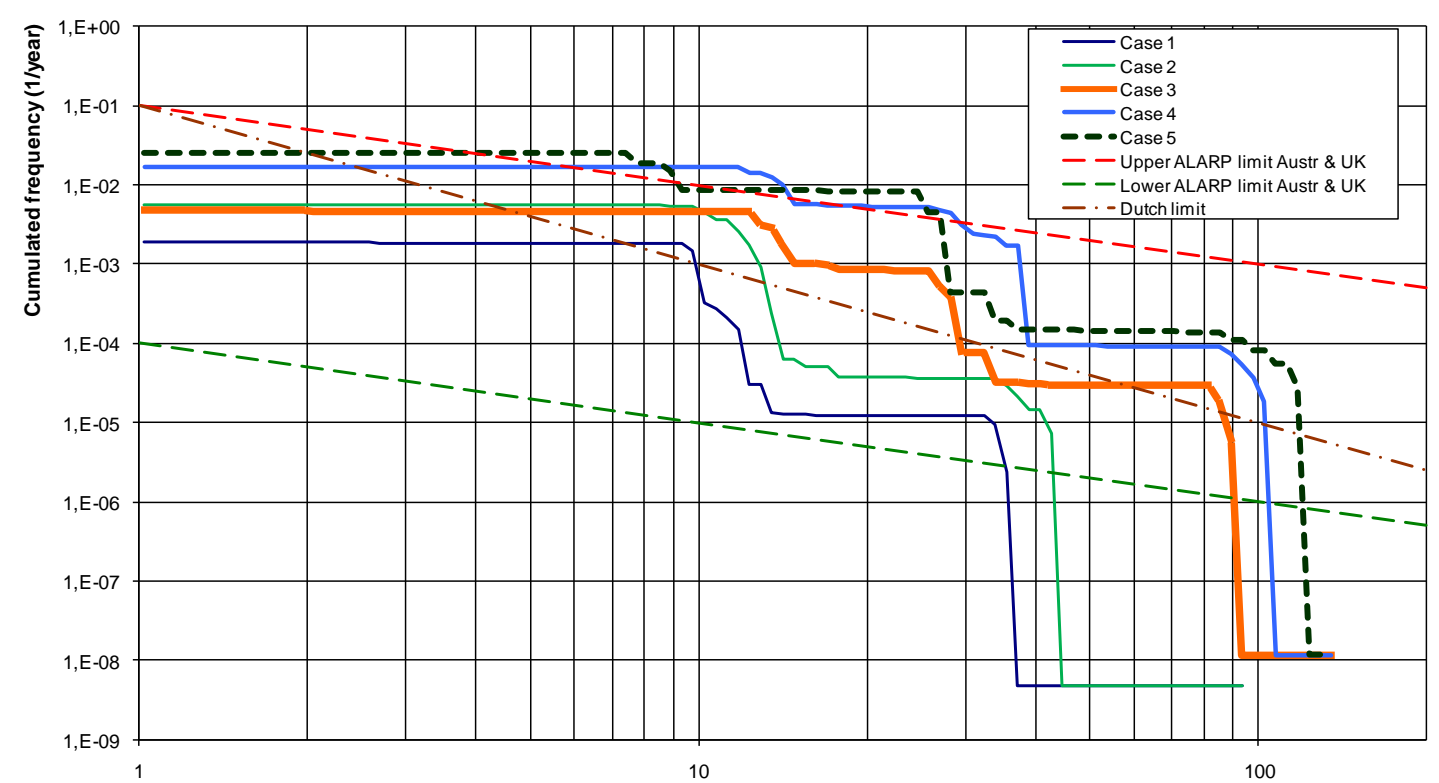

Figure 7. Comparative chart of $\mathrm{F} / \mathrm{N}$ curves for Cases 1 to 5

From the findings it may be concluded that relatively long tunnels $(\sim 3000 \mathrm{~m}$ and over) that are built using only those safety measures imposed by the EC Directive 2004/54/EC fall over the upper ALARP limit. This means that if the tunnel manager wishes to let HGVs and/ or dangerous goods pass through the tunnel, more safety measures should be taken. Thus, risk analysis for deciding whether to let DG pass through the tunnel is indeed necessary. Moreover, since the F/N curves fall over the upper ALARP limit, consideration of alternative routes should be mandatory.

Moreover, a significant observation is that the increased risk ( $\mathrm{F} / \mathrm{N}$ curve close to upper ALARP limit) is mostly existing due to heavy goods vehicles traffic (those that can give fires from $20 \mathrm{MW}$ to $100 \mathrm{MW}$ ) rather than dangerous goods vehicles. As it 
can be observed from Figures $\mathbf{2}-\mathbf{6}$, there is a steep decline in risk just after the maximum number of victims that can be given from a heavy goods vehicle accident. The reasoning behind that is that the proportion of dangerous goods to heavy goods vehicles is relatively low. This observation can raise discussion on whether the two types of loads should be treated differently concerning their access to the tunnel, when the proportion of dangerous goods to heavy goods vehicles is relatively low.

As far as the opening of the tunnel to HGVs and DGs is concerned, the options that the tunnel manager has in order to increase safety in a tunnel and thus allow heavy goods and/ or dangerous goods pass through the tunnel could be the following (OECD, 2001):

- Perform vehicle checks before entrance to the tunnel

- Increase distance between vehicles

- Escort HGVs or DGs

- Prohibition to overtake

- Reduce speed limit

Finally, tunnel managers should run QRA models during the design phase in order to assure that safety measures are adequate and not just take into account the minimum safety measures indicated by legislation.

At this point it should be stressed that the comparison of the F/N curves with ALARP limits for trespassing of HGVs or dangerous goods through the tunnel cannot be the only consideration of a decision maker. There is concern that restrictions on transport of dangerous goods in tunnels will naturally shift this transport on routes probably not designed to support it. Tunnels are usually built to overcome risky routes or congested areas in cities. Consequently, routing long heavy vehicles with dangerous goods on small mountainous routes or in town centers may increase the risks associated to the 
transport with potential higher environmental implications. Thus, it is important to make sure that the risk associated to the transport of dangerous goods in tunnels will be compared to the risk associated to the alternative route. The tunnel classification process, which will be based on the risk analysis, should therefore take into account the risk and inconvenience of transport on the alternative route.

\section{Limitations of the Model}

It is very important to mention some of the provisions of the EC Directive 2004/54/EC that cannot be included in the OECD/PIARC QRA Model. The existence of Cross-connections for emergency services cannot be distinguished from emergency exits, and therefore the potential for faster arrival and increased flexibility of emergency services cannot be taken into account. The existence of lay-bys and the potential of crossing of the central reserve outside each portal are also not possible to be modeled in the OECD/PIARC QRA Model. Furthermore, there is no input possibility for the emergency stations and water supply station intervals, despite the fact that more frequent spacing of these facilities may speed up early communication of an event and facilitate the response actions. Similarly, the existence of traffic signals inside the tunnels, Variable Message Signs (VMS), radio re-broadcasting for emergency services or certain types of public address systems cannot be modeled. However, all these systems may reduce response time of the users of the tunnel in case of an emergency and potentially reduce the casualties. The inability of the QRA model to include all the abovementioned parameters leaves the responsibility to the user to adjust other parameters, such as the delay for stopping approaching traffic or the time to activate emergency ventilation, to account for the effect of these characteristics. However, this is highly subjective and still some of the parameters may not be considered. 


\section{Further research}

Quantitative risk analysis for road tunnels has been a great improvement for measuring tunnels safety. It seems that the OECD/PIARC QRA Model is currently the dominant instrument for such an analysis despite the endogenous problems that it may bear. According to this research results, the $\mathrm{F} / \mathrm{N}$ curves for tunnels with marginal values of the EC Directive classes for length and traffic (at least), lay over the acceptable safety limits of ALARP models. The most interesting further investigation would be to compare the outcome of this model to the outcomes of other models such as CFD simulation models for smoke propagation or other existing models such as the Transportation Risk Analysis tool (Bubbico et al. 2004) or MCS-QRA tool (Pálsson, 2004). The comparison of such models along with sensitivity analysis would be beneficial especially for the evaluation of the proposed risk reduction measures.

\section{References}

Bubbico, R., Di Cave, S. and Mazzarotta, B. 2004, Risk Analysis for Road and Rail Transport of Hazardous Materials: A GIS Approach, Journal of Loss Prevention in the Process Industries 17: 483.

Bubbico, R., Maschio, G., Mazzarotta, B., Milazzo, M.F. and Parisi, E. 2006, Risk Management of Road and Rail Transport of Hazardous Materials in Sicily, Journal of Loss Prevention in the Process Industries 19: 32-38.

Carvel, R. O., Beard, N., Jowitt, W. and Drysdale, D. 2005, Fire Size and Fire Spread in Tunnels with Longitudinal Ventilation Systems, Journal of Fire Sciences 23: 485-518.

EC, 2004, Directive on minimum safety requirements for tunnels in the transEuropean road network, Official Journal of the European Union, L 167 (30.4.2004).

European Thematic Network Fire in Tunnels. 2007, Fire in Tunnels General Report, WTCB, Brussels, Belgium.

Evans, A. 2003, Transport fatal accidents and FN-curves 1967-2001, Research report 073 for the Health and Safety Executive 2003, University College London, UK.

Haack, A. 2002, Current safety issues in traffic tunnels, Tunnelling and Underground Space Technology, 17: 117-127.

INERIS, 2005, Transport of Dangerous goods through road tunnels Quantitative Risk Assessment Model (v. 3.60 and v. 3.61) Reference Manual, Verneuil-enHalatte, France 
Knoflacher H. and Pfaffenbichler, P.C., 2004, A comparative risk analysis for selected Austrian tunnels, Proceedings of $2^{\text {nd }}$ International Conference Tunnel Safety and Ventilation, Graz.

Knoflacher H., Pfaffenbichler P.C. and Nussbaumer H., 2002, Quantitative Risk Assessment of Heavy Goods Vehicle Transport through Tunnels - the Tauerntunnel Case Study, $1^{\text {st }}$ International Conference Tunnel Safety and Ventilation, Graz.

Knoflacher, H. 2001, Quantitative risk analysis model, Tunnel Management International, 3(7): 19-23.

Knoflacher, H. and Pfaffenbichler, P. 2001, A Quantitative Risk Assessment Model for Road Transport Of Dangerous Goods, $80^{\text {th }}$ Annual Meeting Transportation Research Board, Washington.

Lacroix, D., Cassini, P., Hall, R. and Saccomanno, F. 1999, Transport of dangerous goods through road tunnels: an integrated qra model developed under the joint oecd/piarc project ERS2, International ESReDA Seminar, Oslo.

Leitner, A. 2001, The fire catastrophe in the Tauern Tunnel: experience and conclusions for the Austrian guidelines, Tunnelling and Underground Space Technology, 16: 217-223.

Moonis, M., Wilday, J., Wardman, M. and Balmforth, H. 2008, Assessing the safety of delivery and storage of hydrogen, Report PS/08/01, Health \& Safety Laboratory, Derbyshire.

OECD. 2001, Safety in tunnels - Transport of dangerous goods through road tunnels, Organization for Economic Co-operation and Development - OECD Publications, Paris.

Pálsson, G.I. 2004, Risk Management in Hvalfjörður Tunnel, Department of Fire Safety Engineering - Lund University, Report 5136, Lund, Sweden.

Parsons Brinckerhoff Quade \& Douglas, 2006, Risk Analysis Study of Hazardous Materials Trucks through Eisenhower/Johnson Memorial Tunnels: Final Report, June 2006, Co. USA.

PIARC, 2008, Risk analysis for road tunnels, World Road Association (PIARC), France.

SAFE-T, 2008, Appendix 1: Tools for Probabilistic risk assessment, SAFE-T research project report.

\section{Short biographical notes}

Dr Kirytopoulos A. Konstantinos is an Assistant Professor at the Financial and Management Engineering Department at the University of the Aegean (Greece). He holds a PhD on Project Risk Management attained at the National Technical University of Athens (2003) and a Mechanical Engineering Diploma (Bachelor plus MSc equivalent) attained at the same University (1999). His main research interests include but are not limited to Risk Management, Project Management, and Decision Making. He has been involved in numerous research and business projects relevant to his interests and he is frequently publishing his research in international scientific conferences and journals.

Dr. Athanasios A. Rentizelas holds a Mechanical Engineering Degree from the National Technical University of Athens (NTUA - 2001), an MSc in Operations Management with distinction from UMIST, Manchester, UK (2002) and a PhD on Supply Chain Optimisation focused on Biomass from NTUA (2007). He is currently a Research Engineer in the Industrial Management \& Operational Research Sector of NTUA Mechanical Engineering School and Lecturer at the University of Piraeus. His research interests and expertise lie in the areas of optimization, operational research, quantitative 
analysis, supply chain management, logistics, renewable energy sources, investment analysis, and quality management. He has been awarded various awards for his exceptional academic performance, as well as scholarships for postgraduate studies.

Prof. Ilias P. Tatsiopoulos is a Professor in operations management and logistics at the Industrial Management \& Operational Research Sector of the National Technical University of Athens (NTUA). He has been active for several years as a professional production engineer in both industrial and consulting firms and he served as a Lecturer in management information systems at the Economic University of Athens. He studied Mechanical and Industrial Engineering at NTUA (1978) and followed post-graduate studies at the TH Aachen (Germany) and the University of Lancaster (UK) under a NATO grant. He holds a PhD (1983) in Operational Research from the University of Lancaster. He is a member of the Senate of NTUA, ex officio board member of the Greek Institute for Production \& Operations Management and member of the board of the Hellenic Management Association (HMA).

Dr. George Papadopoulos holds a Mechanical Engineering Degree from the National Technical University of Athens (NTUA), an MBA from the University of Wales - college of Cardiff and a PhD from the NTUA. He is currently a Research Engineer in the Industrial Management \& Operational Research Sector of NTUA Mechanical Engineering School. He has working experience in a consulting company and participated in several research projects assigned to the Laboratory of Industrial Management. His research interests are focused in the area of production planning and control related with the design and analysis of customized applications and their integration with Enterprise Resource Planning (ERP) systems. 